\title{
Prevalence of colorectal adenomatous polyps in patients with chronic obstructive pulmonary disease
}

\author{
Eun Mi Chun \\ Seo Woo Kim \\ So Yeon Lim \\ Division of Pulmonary and Critical \\ Care Medicine, Department of \\ Internal Medicine, Ewha Womans \\ University School of Medicine, Seoul, \\ Republic of Korea
}

This article was published in the following Dove Press journal: International Journal of COPD

18 May 2015

Number of times this article has been viewed

Background: Colorectal adenomatous polyps are precancerous lesions of colorectal cancer. The aim of this study was to assess the prevalence of colorectal adenomatous polyps in chronic obstructive pulmonary disease (COPD) patients and determine whether COPD is associated with colorectal malignant potential.

Methods: Subjects who had undergone post-bronchodilator spirometry and colonoscopy and were 40 years or older were selected from the hospital database. COPD was defined as a spirometry in which the ratio of forced expiratory volume in 1 second $\left(\mathrm{FEV}_{1}\right)$ and forced vital capacity (FVC) is $<0.7$ in post-bronchodilator spirometry. The non-COPD group was matched for both age and sex, and were defined as having an $\mathrm{FEV}_{1}, \mathrm{FVC}_{\text {, and }} \mathrm{FEV}_{1} / \mathrm{FVC} \geq 0.7$ in spirometry. Finally, 333 patients were retrospectively reviewed; of this group, 82 patients had COPD.

Results: Among the subjects, 201 patients (60\%) were nonsmokers, while 78 (23\%) were current smokers. The prevalence of colorectal adenomatous polyps was $39 \%(98 / 251)$ in the non-COPD group and 66\% (54/82) in the COPD group. Among 54 patients with adenomatous polyps in the COPD group, 47 had tubular adenoma and seven had villous adenoma. Multiple logistic regression analyses revealed that only COPD patients whom matched to the criteria of COPD by pulmonary function test (odds ratio $2.1,95 \%$ confidence interval: $1.1-3.8 ; P=0.019$ ) were independently associated with colorectal malignant potential.

Conclusion: The risk of colorectal malignant potential in the COPD group was higher than in the non-COPD group. We may suggest that COPD patients should consider regular colonoscopic evaluation to screen for premalignant colon polyps regardless of smoking.

Keywords: COPD, colorectal adenomatous polyp, smoking, chronic obstructive pulmonary disease

\section{Introduction}

Cigarette smoking causes various types of cancers, including in certain organs not directly in contact with the toxic materials of smoke. ${ }^{1}$ Tobacco smoking contains a large number of toxic carcinogens that may bind to DNA, causing genetic damage to normal tissue. Tobacco use has been closely linked to increased risk for colon cancer ${ }^{2-4}$ and has been also associated with colorectal adenomatous polyps. ${ }^{5,6}$ Colorectal adenomatous polyps and certain types of hyperplastic polyps may be transformed to colorectal cancer. In particular, adenomatous polyps are known as more highly potential precursor lesions for colorectal cancers than hyperplastic polyps. ${ }^{7,8}$ Botteri et al found a significant association between smoking and the incidence of adenomatous polyps. ${ }^{9}$ The risk of colorectal adenoma is related to the dose of tobacco carcinogens such as polycyclic aromatic hydrocarbons. ${ }^{10}$ Smokers are associated with an increased frequency of mutations in the mismatch repair enzymes in colorectal neoplasia, showing a twofold greater 
risk of adenoma when exposed to $>25$ pack-years smoking, as compared with nonsmokers. ${ }^{11}$ Smoking is a stronger risk factor for benign hyperplastic polyps than adenomatous polyps. ${ }^{12}$ Tobacco use has been associated with about a two- to threefold risk for adenoma, as compared with nonsmokers. The risks of both hyperplastic polyps and adenomatous polyps are increased with greater cigarette consumption, duration of cigarette use, and pack-years of use. ${ }^{13}$ Hyperplastic polyps may also develop into neoplasia through serrated or microsatellite unstable pathways. ${ }^{14}$

Chronic obstructive pulmonary disease (COPD) is a growing cause of morbidity and mortality and, by the year 2020 , it is estimated to be the fifth leading cause of disability worldwide. ${ }^{15}$ Smoking is the main cause of COPD, but COPD is sometimes independently associated with smoking and age. ${ }^{16}$ Additionally, genetic predisposition, environmental smoke, air pollution, and autoimmune thyroid disease are the proposed risk factors for COPD. ${ }^{17}$ Although smoking is well known as the cause of adenomatous polyps, few studies have evaluated the association between colorectal adenomatous polyps and COPD. The goal of this study was to assess the prevalence of colorectal adenomatous polyps in COPD patients and determine whether COPD is associated with colorectal malignant potential.

\section{Materials and methods}

Our study was a retrospective, case-control study using data from the Ewha Womans University School of Medicine, Mokdong Hospital (Seoul, Republic of Korea) database from between January 2003 and April 2012. Subjects were patients aged 40 years and older who had undergone post-bronchodilator spirometry according to American Thoracic Society (ATS) standard/European Respiratory Society (ERS) guidelines and colonoscopy. ${ }^{18}$ A participant's data was retrieved from the list of patients that had undergone both colonoscopy and spirometry in the gastroenterology department. COPD patients and non-COPD patients were divided according to the results of pulmonary function tests, especially by forced expiratory volume in 1 second $\left(\mathrm{FEV}_{1}\right)$ and $\mathrm{FEV}_{1} /$ forced vital capacity (FVC). COPD was defined as the presence of a fixed ratio of $\mathrm{FEV}_{1}$ and $\mathrm{FVC}$ of $<0.7$ in post-bronchodilator spirometry. The non-COPD group was matched for both age and sex, and were defined as having an $\mathrm{FEV}_{1}, \mathrm{FVC}$, and $\mathrm{FEV}_{1} / \mathrm{FVC}$ $\geq 0.7$ in spirometry. Finally, 333 patients were retrospectively reviewed and matched with inclusion criteria, and the following data were collected: age, sex, height, weight, smoking history, comorbidities, colonoscopic findings, and pathology. Smoking exposure was documented in the form of pack-years (number of packs smoked per day multiplied by the number of years smoked). Smokers were divided into the following three groups: 1) nonsmokers: those who had never smoked during their lifetime; 2) current smokers: those who had smoked $>10$ packs of cigarettes during their lifetime and who were smoking at the time of the survey; and 3) former smokers: those who had quit smoking $>1$ year ago. Experienced gastroenterologists who were blinded to the status of the subjects performed the colonoscopies. Polyps were photo-documented and biopsied for histologic confirmation. Gastroenterologists described the sizes, location sites, and morphology of the colon polyps in the computer data. The data of colonoscopic and pathologic findings of colon polyps were retrospectively analyzed. This study was approved by the Institutional Review Board of the Ewha Womans University School of Medicine, Mokdong Hospital (ECT 13-29A-21) and the requirements for written informed consent before the study were waived because of the retrospective nature of this study.

\section{Statistical analysis}

Statistical analysis was performed by using SPSS 13 (SPSS Inc., Chicago, IL, USA) for interpretation of the effect of several factors to colorectal polyps. Descriptive statistics including means for continuous data, proportions for categorical data, and standard deviations were calculated. Baseline characteristics were compared between the COPD group and the non-COPD group classified using chi-square or Fisher's exact test for categorical data and Mann-Whitney $U$ or $t$-tests for continuous data. Univariate analyses were performed and all risk factors whose association had a $P$-value $<0.1$ were entered into multivariate logistic regression models. The relation of COPD to colorectal polyps was analyzed using multiple logistic regression to adjust for age and smoking and estimate odds ratio (OR) and a 95\% confidence interval (CI). The OR and $95 \%$ CIs were calculated by regression models. Statistical significance was defined as a $P$-value of $<0.05$.

\section{Results}

A total of 333 patients were enrolled in the present study, of which 251 were non-COPD patients, while 82 were COPD patients. Table 1 shows the demographic data of the non-COPD group and the COPD group. The mean age was 65 years in both groups, and about $90 \%$ of the patients were male. Body mass index (BMI) was significantly higher in non-COPD patients than COPD patients $(25.1 \pm 7.7$ versus $22.4 \pm 8.7, P<0.001)$. Of all subjects, 201 (60\%) were nonsmokers and $78(23 \%)$ were current smokers. The number of lifetime nonsmokers was higher in the non-COPD group 
Table I Baseline characteristics of patients in the COPD group and non-COPD group

\begin{tabular}{|c|c|c|c|}
\hline Variable & $\begin{array}{l}\text { Non-COPD } \\
(n=25 I)\end{array}$ & $\begin{array}{l}\text { COPD } \\
(n=82)\end{array}$ & $P$-value \\
\hline Age (years) & $64 \pm 6$ & $65 \pm 9$ & 0.385 \\
\hline Male:female & $\begin{array}{l}235(94 \%): \\
16(6 \%)\end{array}$ & $\begin{array}{l}74(90 \%): \\
8(10 \%)\end{array}$ & 0.304 \\
\hline BMI $\left(\mathrm{kg} / \mathrm{m}^{2}\right)$ & $25.1 \pm 7.7$ & $22.4 \pm 8.7$ & $<0.001$ \\
\hline \multicolumn{4}{|l|}{ Smoking } \\
\hline Lifetime nonsmoker & I 74 (70\%) & 27 (33\%) & \\
\hline Former smoker & $25(10 \%)$ & $29(35 \%)$ & \\
\hline Current smoker & $52(20 \%)$ & $26(32 \%)$ & \\
\hline Pack-years & $7.9 \pm \mid 4.1$ & $23.8 \pm 27.1$ & $<0.001$ \\
\hline \multicolumn{4}{|l|}{ Pulmonary function test } \\
\hline $\mathrm{FVC} \mathrm{(L)}$ & $5.0 \pm 2.2$ & $3.2 \pm 0.8$ & $<0.001$ \\
\hline FVC (predicted \%) & $98.2 \pm 65.7$ & $87.3 \pm 19.0$ & $<0.001$ \\
\hline $\mathrm{FEV}_{1}(\mathrm{~L})$ & $2.9 \pm 0.5$ & $1.9 \pm 0.4$ & $<0.001$ \\
\hline FEV (predicted \%) & $106.3 \pm 13.3$ & $73.4 \pm 20.4$ & $<0.001$ \\
\hline $\mathrm{FEV}_{\mathrm{I}} / \mathrm{FVC}(\%)$ & $80.3 \pm 6.1$ & $59.1 \pm 10.5$ & $<0.001$ \\
\hline \multicolumn{4}{|l|}{ Comorbidity, $\mathrm{n}$} \\
\hline Diabetes & 23 & 11 & \\
\hline Hypertension & 81 & 43 & \\
\hline Lung cancer & I & 16 & \\
\hline Gastrointestinal cancer & 10 & 1 & \\
\hline $\begin{array}{l}\text { Radiological inactive } \\
\text { tuberculosis scar }\end{array}$ & 36 & 11 & \\
\hline \multicolumn{4}{|l|}{ GOLD classification } \\
\hline Mild $\left(\mathrm{FEV}_{1} \geq 80 \%\right)$ & & $34(42 \%)$ & \\
\hline Moderate $(50 \% \leq \mathrm{FEV},<80 \%)$ & & $34(42 \%)$ & \\
\hline Severe $(30 \% \leq \mathrm{FEV},<50 \%)$ & & $12(15 \%)$ & \\
\hline Very severe $(\mathrm{FEV}, \leq 30 \%)$ & & $2(2 \%)$ & \\
\hline
\end{tabular}

Note: Data are presented as mean \pm standard deviation, number, or number (\%). Abbreviations: COPD, chronic obstructive pulmonary disease; BMI, body mass index; FEV, forced expiratory volume in I second; FVC, forced vital capacity; GOLD, Global Initiative for Chronic Obstructive Lung Disease.

than in the COPD group, while the number of pack-years was significantly higher in the COPD group, as compared with the non-COPD group $(23.8 \pm 27.1$ versus $7.9 \pm 14.1, P<0.001$, respectively). $\mathrm{FEV}_{1} / \mathrm{FVC}$ (predicted \%) was significantly lower in the COPD group than in the non-COPD group (59.1 \pm 10.5 versus $80.3 \pm 6.1, P<0.001$, respectively). FEV (predicted \%) was also significantly lower in the COPD group than in the non-COPD group $(73.4 \pm 20.4$ versus $106.3 \pm 13.3, P<0.001$, respectively). The majority of the COPD patients belonged to the Global Initiative for Chronic Obstructive Lung Disease (GOLD) stages I and II. Those patients who belonged to GOLD stages III and IV were only $17 \%$ (14/82). Table 2 shows the results of pathologic findings by colonoscopic biopsy between the COPD group and the non-COPD group. Carcinoembryonic antigen (CEA) value of serum $\geq 10 \mathrm{ng} / \mathrm{mL}$ was significantly higher in the COPD group than in the non-COPD group $(P<0.001)$. The prevalence of adenomatous polyps was $39 \%(98 / 251)$ in the
Table 2 The results for pathologic findings of colonoscopic biopsy between the COPD group and non-COPD group

\begin{tabular}{|c|c|c|c|}
\hline Variable & $\begin{array}{l}\text { Non-COPD } \\
(n=25 I)\end{array}$ & $\begin{array}{l}\text { COPD } \\
(n=82)\end{array}$ & $P$-value \\
\hline CEA & & & $<0.001$ \\
\hline Value $<5 \mathrm{ng} / \mathrm{mL}$ & 229 (91\%) & $49(60 \%)$ & \\
\hline $5-10 \mathrm{ng} / \mathrm{mL}$ & $16(6 \%)$ & 17 (2।\%) & \\
\hline Value $\geq 10 \mathrm{ng} / \mathrm{mL}$ & $6(2 \%)$ & $16(20 \%)$ & \\
\hline \multicolumn{4}{|l|}{ Colonoscopic finding } \\
\hline Normal finding ${ }^{a}$ & I 23 (49\%) & $24(29 \%)$ & 0.002 \\
\hline \multicolumn{4}{|l|}{ Confirmed by biopsy } \\
\hline Hyperplastic polyp & $22(9 \%)$ & 7 (9\%) & 0.949 \\
\hline \multicolumn{4}{|l|}{ Adenomatous polyp } \\
\hline Tubular adenoma & $89(36 \%)$ & 47 (57\%) & $<0.001$ \\
\hline Villous adenoma & $9(4 \%)$ & 7 (9\%) & 0.069 \\
\hline Adenocarcinoma & $5(2 \%)$ & $5(6 \%)$ & 0.059 \\
\hline Inflammatory polyp & $34(14 \%)$ & $13(16 \%)$ & 0.602 \\
\hline
\end{tabular}

Notes: Data are presented as number (\%). ${ }^{\mathrm{a} A}$ normal finding included a normal, hemorrhoid, and/or diverticulum finding by colonoscopy.

Abbreviations: COPD, chronic obstructive pulmonary disease; CEA, carcinoembryonic antigen.

non-COPD group and 66\% (54/82) in the COPD group. Ten patients had confirmed adenocarcinoma, $2 \%$ (five) in the non-COPD group and 6\% (five) in the COPD group, respectively. The incidence of tubular adenomas was significantly higher in the COPD group than in the non-COPD group $(P<0.001)$. There was no statistically significant difference in the prevalence of adenomatous polyps between GOLD criteria within the COPD group (Table 3). Smoking status and BMI showed significant association with malignant potential, as verified by the univariate logistic regression model. In contrast, the combination of smoking status and BMI could not be verified by the adjusted multiple logistic regression. Multiple logistic regression analyses revealed that only COPD combined status which defined pulmonary function test (adjusted OR $=2.1,95 \%$ CI: $1.1-3.8 ; P=0.019)$ was independently associated with colorectal malignant potential (Table 4).

\section{Discussion}

We found a significant association between the presence of COPD and the incidence of colorectal adenomatous polyps. The unique finding of this research was that only COPD, regardless of the status of smoking, has an apparent correlation with colorectal adenomatous polyps. Several studies demonstrated that smoking is the important cause of colorectal polyps and colon cancer. ${ }^{2-5,19}$ Smoking history, including former smokers and current smokers, is associated with an increased risk of colorectal cancer. ${ }^{20}$ Liang et al demonstrated a significantly increased risk for current smokers and 
Table 3 The analyses for colonoscopic findings of COPD patients by GOLD classification

\begin{tabular}{|c|c|c|c|c|}
\hline Variable & $\begin{array}{l}\text { FEV }_{1} \geq \mathbf{8 0} \% \\
(n=34)\end{array}$ & $\begin{array}{l}\mathbf{5 0} \% \leq \mathbf{F E V}_{1}<\mathbf{8 0} \% \\
(\mathrm{n}=\mathbf{3 4})\end{array}$ & $\begin{array}{l}\text { FEV }_{1}<\mathbf{5 0} \% \\
(n=\mid 4)\end{array}$ & $P$-value \\
\hline \multicolumn{5}{|l|}{ Colonoscopic finding } \\
\hline Normal finding ${ }^{\mathrm{a}}$ & 11 & 9 & 4 & 0.866 \\
\hline \multicolumn{5}{|l|}{ Confirmed by biopsy } \\
\hline Hyperplastic polyp & 3 & 3 & I & 0.979 \\
\hline \multicolumn{5}{|l|}{ Adenomatous polyp } \\
\hline Tubular adenoma & 20 & 18 & 9 & 0.750 \\
\hline Villous adenoma & 3 & 2 & 2 & 0.637 \\
\hline Advanced cancer & 0 & 3 & 2 & 0.117 \\
\hline Inflammatory polyp & 5 & 8 & 0 & 0.124 \\
\hline
\end{tabular}

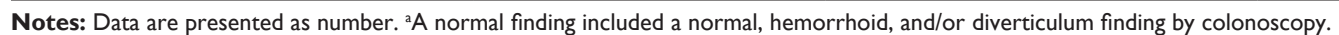

Abbreviations: COPD, chronic obstructive pulmonary disease; GOLD, Global Initiative for Chronic Obstructive Lung Disease; FEV , forced expiratory volume in I second.

former smokers in terms of mortality related with colorectal cancers (relative risk $=1.4$ versus 1.15 , respectively). ${ }^{21}$ Many studies have demonstrated that long-term cigarette smokers had a two- to threefold increased risk of colorectal adenoma. ${ }^{4}$ Shin et al showed that former smokers (OR $=1.31$, 95\% CI: 1.04-1.65) and current smokers (OR $=1.70,95 \%$ CI: 1.37-2.11) had increased risks for adenomas, as compared with nonsmokers in the Korean population. ${ }^{22}$ A previous study revealed that cigarette smoking has a strong relationship with the development of colorectal adenomas but is not closely associated with colorectal cancer. The main effect of smoking on the colorectal adenoma-carcinoma sequence may occur in the earlier stages of the formation of adenoma and the development of carcinoma in situ. ${ }^{23}$ Unknown sequential processes of genetic alterations in the normal colon epithelium may transform to adenoma and then change to carcinoma. ${ }^{7}$ Cigarette smoking induces continuous inflammation and infection throughout the human body. Cigarette smoking can facilitate tumor growth by induction of angiogenesis and suppression of cell-mediated immunity. ${ }^{24}$ Many malignancies arise from the sites of infections and inflammations. ${ }^{25}$
The strongest association of chronic inflammation with malignancies is colon carcinogenesis in subjects with chronic inflammatory bowel diseases ${ }^{26}$ Cyclooxygenase (COX)-2 converts arachidonic acid to prostaglandins inducing inflammatory reactions in damaged tissues. Nonsteroidal anti-inflammatory drugs (NSAIDs) and aspirin inhibit COX-1 and COX-2. The long-term uses of aspirin and NSAIDs reduce colon cancer risk by $40 \%-50 \%$ and have been tried as chemopreventive agents for lung cancer, colon cancer, and stomach cancer. ${ }^{27,28}$ Although the most common cause of COPD is known to be cigarette smoking, the incidence of nonsmokers as a portion of COPD patients is increasing because of occupationally associated chronic inflammations and indoor air pollution caused by the burning of biomass fuels. ${ }^{29}$ Although there have been a lot of studies regarding the association between smoking and colorectal adenomatous polyps, there is no research to determine whether COPD is the cause of colorectal adenomatous polyps and colon cancer. The present study suggests that the presence of COPD is the cause of colorectal adenomatous polyps regardless of a history of smoking. Smoking induces chronic inflammatory situations in the entire body, including

Table 4 Univariate and multivariate analysis of factors contributing to colorectal malignant potential ${ }^{\mathrm{a}}$

\begin{tabular}{|c|c|c|c|c|}
\hline Variable & $\begin{array}{l}\text { Univariate } \\
\text { hazard ratio }(95 \% \mathrm{Cl})\end{array}$ & $P$-value & $\begin{array}{l}\text { Multivariate } \\
\text { hazard ratio }(95 \% \mathrm{Cl})\end{array}$ & $P$-value \\
\hline Age & $1.024(0.992-1.056)$ & 0.144 & $1.012(0.979-1.046)$ & 0.486 \\
\hline Male sex & $2.485(0.960-6.431)$ & 0.061 & $2.490(0.900-6.888)$ & 0.079 \\
\hline BMI $\left(\mathrm{kg} / \mathrm{m}^{2}\right)$ & $0.894(0.829-0.964)$ & 0.004 & $0.931(0.858-1.010)$ & 0.085 \\
\hline Smoking status & & & & 0.895 \\
\hline Nonsmoker & I & & I & \\
\hline Former smoker & $1.930(1.052-3.54 I)$ & 0.034 & I.I $77(0.598-2.314)$ & \\
\hline Current smoker & $1.356(0.789-2.303)$ & 0.260 & I.04I (0.589-I.839) & \\
\hline COPD patients & $2.357(1.417-3.923)$ & 0.001 & $2.058(1.126-3.764)$ & 0.019 \\
\hline
\end{tabular}

Notes: Multiple logistic regression analysis was adjusted for age, sex, BMI, smoking status, and COPD combined. ${ }^{\mathrm{a} C o l o r e c t a l ~ m a l i g n a n t}$ potential includes both adenomatous polyps and adenocarcinoma on pathologic findings of colonoscopy.

Abbreviations: BMI, body mass index; $\mathrm{Cl}$, confidence interval; COPD, chronic obstructive pulmonary disease. 
the lungs. Most of the COPD patients have chronic inflammatory lung diseases and their immune conditions are weaker than in non-COPD subjects. This study also demonstrated the association between BMI and COPD. Abdominal obesity is a strong independent risk factor of insulin resistance in men. ${ }^{30-32}$ Several studies showed that adipose tissue distribution, especially around the waist, was the main factor in the association between obesity and adenomatous polyps. ${ }^{33,34}$ In contrast, our study showed that COPD patients with a low BMI were associated with a high incidence of colorectal adenomatous polyps. COPD patients generally have low BMI because of chronic inflammation, and the association between BMI and adenomatous polyps was inverse in COPD patients.

The present study has several limitations. First, this study was performed only in an university hospital and was not a multicenter study. However, the study hospital was an average university hospital located in a city. Therefore, the characteristics of the study population might be similar to that in other urban hospitals. Second, some important factors affecting the development of malignant potential, such as alcohol history, family history of colon cancer, other gastrointestinal diseases, and use of NSAIDs, were not collected due to the limitations of a retrospective study. The main aim of the present study was to evaluate the association between colorectal adenomatous polyps and COPD patients (defined by a spirometric criterion). Therefore, this limitation will be supported by a prospective randomized study including the individual history. Third, no clinical diagnosis of COPD was made in the present study. However, most early-stage COPD patients do not feel respiratory symptoms and the spirometric criteria may be an objective method for diagnosis of COPD in a population-based study. Fourth, most of the COPD subjects were male patients. The low prevalence of COPD patients among Korean females is due to small incidence of female smokers.

\section{Conclusion}

The present research demonstrates that there was an association with increased colorectal adenomatous polyps in COPD patients, regardless of their smoking status. The results of our study present the development of the possibility that many kinds of chronic inflammatory conditions are the important risk factors that evoke colon malignancy.

A regular colonoscopy may be helpful for detecting premalignant colorectal adenomatous polyps or colon cancers in COPD patients regardless of whether the COPD patients are nonsmokers or former smokers. A large randomized prospective study is needed to confirm the results of the present study.

\section{Disclosure}

The authors report no conflict of interests in this work.

\section{References}

1. Gandini S, Botteri E, Iodice S, et al. Tobacco smoking and cancer: a meta-analysis. Int J Cancer. 2008;1:155-164.

2. Giovannucci E, Colditz GA, Stampfer MJ, et al. A prospective study of cigarette smoking and risk of colorectal adenoma and colorectal cancer in U.S. women. J Natl Cancer Inst. 1994;86:192-199.

3. Terry P, Ekbom A, Lichtenstein P, Feychting M, Wolk A. Long-term tobacco smoking and colorectal cancer in a prospective cohort study. Int J Cancer. 2001;91:585-587.

4. Giovannucci E. An updated review of the epidemiological evidence that cigarette smoking increases risk of colorectal cancer. Cancer Epidemiol Biomarkers Prev. 2001;10:725-731.

5. Almendingen K, Hofstad B, Trygg K, Hoff G, Hussain A, Vatn MH Smoking and colorectal adenomas: a case-control study. Eur J Cancer Prev. 2000;9:193-203.

6. Erhardt JG, Kreichgauer HP, Meisner C, Bode JC, Bode C. Alcohol, cigarette smoking, dietary factors and the risk of colorectal adenomas and hyperplastic polyps - a case control study. Eur J Nutr. 2002;41:35-43.

7. Fearon ER, Vogelstein B. A genetic model for colorectal tumorigenesis Cell. 1990;61:759-767.

8. Hill MJ, Morson BC, Bussey HJ. Aetiology of adenoma - carcinoma sequence in large bowel. Lancet. 1978;1:245-247.

9. Botteri E, Iodice S, Raimondi S, Maisonneuve P, Lowenfels AB. Cigarette smoking and adenomatous polyps: a meta-analysis. Gastroenterology. 2008;134:388-395.

10. Tranah GJ, Giovannucci E, Ma J, Fuchs C, Hankinson SE, Hunter DJ. Epoxide hydrolase polymorphisms, cigarette smoking and risk of colorectal adenoma in the Nurses' Health Study and the Health Professionals Follow-up Study. Carcinogenesis. 2004;25:1211-1218.

11. Yu JH, Bigler J, Whitton J, Potter JD, Ulrich CM. Mismatch repair polymorphisms and colorectal polyps: hMLH1-93G > A variant modifies risk associated with smoking. Am J Gastroenterol. 2006;101:1313-1319.

12. Ji BT, Weissfeld JL, Chow WH, Huang WY, Schoen KE, Hayes RB Tobacco smoking and colorectal hyperplastic and adenomatous polyps. Cancer Epidemiol Biomarkers Prev. 2006;15:897-901.

13. Shrubsole MJ, Wu H, Ness RM, Shyr Y, Smalley WE, Zheng W. Alcohol drinking, cigarette smoking, and risk of colorectal adenomatous and hyperplastic polyps. Am J Epidemiol. 2008;167:1050-1058.

14. Leggett B, Whitehall V. Role of the serrated pathway in colorectal cancer pathogenesis. Gastroenterology. 2010;138:2088-2100.

15. Michaud CM, Murray CJ, Bloom BR. Burden of disease-implications for future research. JAMA. 2001;285:535-539.

16. Hospers JJ, Schouten JP, Weiss ST, Rijcken B, Postma DS. Asthma attacks with eosinophilia predict mortality from chronic obstructive pulmonary disease in a general population sample. Am J Respir Crit Care Med. 1999;160(6):1869-1874.

17. Birring SS, Brightling CE, Bradding P, et al. Clinical, radiologic, and induced sputum features of chronic obstructive pulmonary disease in nonsmokers: a descriptive study. Am J Respir Crit Care Med. 2002; 166(8):1078-1083.

18. Celli BR, MacNee W; ATS/ERS Task Force. Standards for the diagnosis and treatment of patients with COPD: a summary of the ATS/ ERS position paper. Eur Respir J. 2004;23:932-946.

19. Anderson JC, Stein B, Kahi CJ, Rajapakse R, Walker G, Alpern Z. Association of smoking and flat adenomas: results from an asymptomatic population screened with a high-definition colonoscope. Gastrointest Endosc. 2010;71(7):1234-1240. 
20. Colditz GA, Yaus KP. Smoking causes colon carcinoma. Cancer. 2004;100(2):223-224.

21. Liang PS, Chen TY, Giovannucci E. Cigarette smoking and colorectal cancer incidence and mortality: systematic review and meta-analysis. Int J Cancer. 2009; 124:2406-2415.

22. Shin A, Hong CW, Sohn DK, et al. Associations of cigarette smoking and alcohol consumption with advanced or multiple colorectal adenoma risks: a colonoscopy-based case-control study in Korea. Am J Epidemiol. 2011;174(5):552-562.

23. Terry MB, Neugut AI. Cigarette smoking and the colorectal adenomacarcinoma sequence: a hypothesis to explain the paradox. Am J Epidemiol. 1998;147:903-910.

24. O’Byrne KJ, Dalgleish AG, Browning MJ, Steward WP, Harris AL. The relationship between angiogenesis and the immune response in carcinogenesis and progression of malignant disease. Eur J Cancer. 2000; 36:151-169.

25. Shacter E, Weitzman SA. Chronic inflammation and cancer. Oncology (Williston Park). 2002;16:217-226.

26. Coussens LM, Werb Z. Inflammation and cancer. Nature. 2002; 420(6917):860-867.

27. García-Rodríguez LA, Huerta-Alvarez C. Reduced risk of colorectal cancer among long-term users of aspirin and nonaspirin nonsteroidal anti-inflammatory drugs. Epidemiology. 2001;12:88-93.
28. Baron JA, Sandler RS. Nonsteroidal anti-inflammatory drugs and cancer prevention. Annu Rev Med. 2000;51:511-523.

29. Salvi SS, Barnes PJ. Chronic obstructive pulmonary disease in nonsmokers. Lancet. 2009;374:733-743.

30. Giovannucci E, Ascherio A, Rimm EB, Colditz GA, Stanpfer MJ, Willett WC. Physical activity, obesity, and risk for colon cancer and adenoma in men. Ann Intern Med. 1995;122:327-344.

31. Kono S, Handa $\mathrm{K}$, Hayabuchi $\mathrm{H}$, et al. Obesity, weight gain and risk of colon adenomas in Japanese men. Jpn J Cancer Res. 1999;90(8): 805-811.

32. Morimoto LM, Newcomb PA, Ulrich CM, Bostick RM, Lais CJ, Potter JD. Risk factors for hyperplastic and adenomatous polyps: evidence for malignant potential? Cancer Epidemiol Biomarkers Prev. 2002;11: 1012-1018

33. Shinchi K, Kono S, Honjo S, et al. Obesity and adenomatous polyps of the sigmoid colon. Jpn J Cancer Res. 1994;85:479-484.

34. Otake S, Takeda H, Suzuki Y, et al. Association of visceral fat accumulation and plasma adiponectin with colorectal adenoma: evidence for participation of insulin resistance. Clin Cancer Res. 2005;11: 3642-3646.
International Journal of COPD

\section{Publish your work in this journal}

The International Journal of COPD is an international, peer-reviewed journal of therapeutics and pharmacology focusing on concise rapid reporting of clinical studies and reviews in COPD. Special focus is given to the pathophysiological processes underlying the disease, intervention programs, patient focused education, and self management protocols.

\section{Dovepress}

This journal is indexed on PubMed Central, MedLine and CAS. The manuscript management system is completely online and includes a very quick and fair peer-review system, which is all easy to use. Visit http://www.dovepress.com/testimonials.php to read real quotes from published authors. 